\title{
A cross-sectional study to determine the prevalence of obesity, overweight and weight awareness among the students of a private medical college in Khulna
}

\author{
${ }^{*}$ MA Hasanat ${ }^{1}$, S Paroi ${ }^{2}$, A Begum $^{3}$, U Salma4 ${ }^{4}$ SF Yeasmin ${ }^{5}$
}

\begin{abstract}
Background: Medical education is stressful throughout the whole course. Due to the medical curriculum and the examination pattern leads to psychological stress. Stressful condition leads to irregularity in diet, frequent fast food consumption \& lack of exercise, each being considered as an important risk factor leading to overweight and obesity. Hence, this study was undertaken to determine the prevalence of obesity, overweight and weight awareness among the medical students. Objectives: Determination of BMI status of undergraduate medical students to evaluate their weight awareness, prevalence of overweight and obesity and also find out the relationship of the following risk factors with obesity \& overweight; i) Opinion about self-image, ii) Physical activity and iii) Frequency of fast food consumption. Methods: A descriptive cross sectional study was conducted on 131 preclinical medical students of Ad-din Akij Medical College, Khulna from January 2018 to April 2018. Height and weight of 131 preclinical students were measured and Body Mass Index was calculated and categorized according to WHO criteria. Results: Out of 131 students $62 \%$ come under normal weight category, $21 \%$ come under overweight category, $10 \%$ come under obese category and $7 \%$ come under underweight category. Conclusion: Overweight is a rising problem among the medical students. Sedentary life style and frequency of fast food consumption was high among the overweight and obese students. This study itself created awareness about their weight and promote physical activity among the medical students.
\end{abstract}

Keywords: BMI, Medical students, Underweight, Overweight, Obesity.

1. Dr. Md. Abul Hasanat, Associate Professor, Department of Physiology, Gazi Medical College, Khulna. Email: drhasanat06@gmail.com

2. Dr. Silvia Paroi, Assistant Professor, Department of Community Medicine, Ad-din Akij Medical College, Khulna.

3. Dr. Arifa Begum, Assistant Professor, Department of Physiology, Gazi Medical College, Khulna.

4. Dr. Umme Salma, Lecturer, Department of Biochemistry, Gazi Medical College, Khulna.

5. Dr. Syeda Farzana Yeasmin, Assistant Professor, Department of Gynaecology \& Obstetrics, Ad-din Akij Medical College Hospital, Khulna. 
Introduction

Obesity is a medical condition in which excess body fat has accumulated in the body and produces adverse effect on health, leading to reduced life expectancy and in creased health problems. ${ }^{1}$ Burden of noncommunicable diseases in general and cardiovascular disease (CVD) in particular is largely attributed to obesity both in developed as well as in developing countries. Obesity is major public health concern globally. Worldwide obesity has nearly doubled since 1980 . In1997, the WHO formally recognized obesity as a global epidemic. As of 2005 the WHO estimates showed thatat least 400 million adults i.e. $9.8 \%$ are obese, with high rates among women than men. In 2008; more than 1.4 billion adults of age 20 or older were over weight. Of these over 200 million men and nearly 300 million women were obese. Overweight and obesity are the fifth leading risk for global deaths. ${ }^{2}$ Health personnel are important promoters and role models for maintaining a healthy lifestyle for the general population. Studies on medical students and health personnel in many countries, however, suggest that obesity is a problem among these population groups. ${ }^{3}$ The professional students, including medical students are in a high risk side when obesity is concerned. This is mainly because of the modernization and industrialization which has lead to sedentary life style and unhealthy eating pattern. ${ }^{4}$ Besides, underweight is also another cause resulting in certain diseases like malnutrition, anemia, mortality and morbidity. So, it is necessary to create awareness among students right from the beginning. BMI can be used as a simple method to assess the body weight of an individual. Body mass index calculated using the formula: weight in kgs/height2 in meters. ${ }^{5}$ Obesity and overweight in medical students is gradually becoming a health problem in many developing countries. Medical students are more prone to obesity due to their lifestyle with less physical activity and disordered eating habits. Moreover medical education is stressful throughout the whole course. Due to the medical curriculum and the examination pattern leads to psychological stress. Stressful condition leads to irregularity in diet, frequent fast food consumption \& lack of exercise, each being considered as an important risk factor leading to overweight and obesity. As there are few studies in our country among medical students, this study was undertaken to determine the prevalence of obesity, overweight and weight awareness among the medical students. The results of this study will help to increase knowledge and awareness about diet, exercise and weight maintenance among medical students.

\section{Materials and methods}

A cross-sectional study was conducted on 131 medical students of $2 \mathrm{nd}, 3 \mathrm{rd} \& 4$ th year of Ad-din Akij Medical College, Khulna, Bangladesh from January 2018 to April 2018. Their body weight and height were measured, and a standardized questionnaire was used to collect information on their physical activities and dietary intake. The investigator obtained permission from the students, prior to the data collection and assured confidentiality to the subject to get their cooperation and explained the purpose of the study. Using cut off points from World Health Organization (WHO) criteria (Table 01), BMI less than 18.5 was considered underweight, 18.5 to 24.99 normal weight, 25 to 29.9 was overweight and 30 or above as obese. Statistical analysis was done by using SPSS version 16 .

\section{Results}

131 medical students were participated in the study with the age ranged from 19 to 23 years. Among them 51 (38.9\%) were male and $80(61.07 \%)$ were female. (Figure 01) 


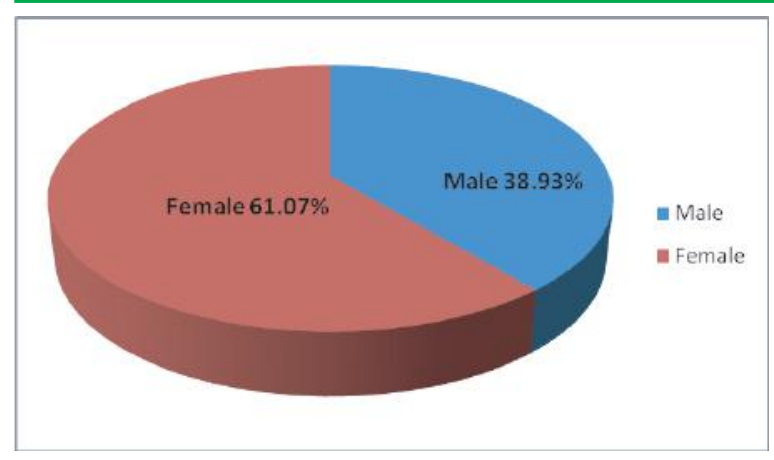

\section{Figure 01: Percentage of male \& female students}

The mean BMI of the male students $22.51 \pm 1.75$ and females $23.74 \pm 1.42$, the prevalence of overweight was $21.37 \%$ and the obesity was $9.92 \%$ while $61.83 \%$ were within normal range and $6.87 \%$ were underweight (Figure 02) according to WHO guidelines.

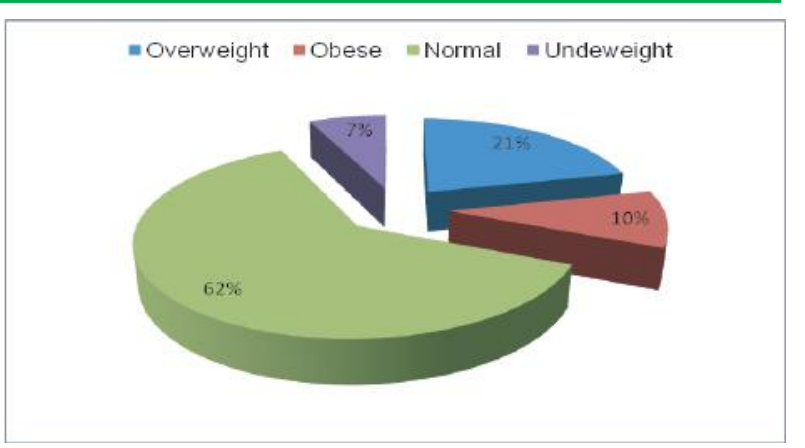

Figure 02: Prevalence of overweight \& Obesity

$81.25 \%$ female \& $74.50 \%$ male students thought that they were appropriate in weight while $10 \%$ female \& $11.76 \%$ male student's felt that they were overweight. Only $3.75 \%$ female and $3.92 \%$ male student's felt that they were obese and 5\% female \& $9.80 \%$ male students thought that they were underweight. (Table 01)

Table 01: Opinion about self-image

\begin{tabular}{|l|l|l|l|l|}
\hline $\begin{array}{c}\text { Opinion about } \\
\text { self-image }\end{array}$ & $\begin{array}{c}\text { No. of female } \\
\text { students (N=80) }\end{array}$ & Percentage & $\begin{array}{c}\text { No. of male } \\
\text { students (N=51) }\end{array}$ & Percentage \\
\hline Appropriate & 65 & $81.25 \%$ & 38 & $74.50 \%$ \\
\hline Underweight & 4 & $5 \%$ & 5 & $9.80 \%$ \\
\hline Overweight & 8 & $10 \%$ & 6 & $11.76 \%$ \\
\hline Obese & 3 & $3.75 \%$ & 2 & $3.92 \%$ \\
\hline
\end{tabular}

Overweight and obese students are doing less physical activity when compare to normal \& underweight students. (Table 02)

Table 02: BMI \& Physical activity

\begin{tabular}{|l|c|c|c|c|}
\hline \multirow{2}{*}{\multicolumn{1}{|c|}{ BMI (kg/m $\left.{ }^{2}\right)$}} & \multicolumn{4}{|c|}{ Physical Exercise } \\
\cline { 2 - 5 } & No exercise & Regularly & Occasionally & Total \\
\hline Overweight $>24.9$ & $17(60.71 \%)$ & $5(17.86 \%)$ & $6(21.43 \%)$ & $28(100 \%)$ \\
\hline Obese $>30$ & $8(61.54 \%)$ & $2(15.38 \%)$ & $3(23.08 \%)$ & $13(100 \%)$ \\
\hline Appropriate $18.5-24.9$ & $28(34.57 \%)$ & $34(41.98 \%)$ & $19(23.46 \%)$ & $81(100 \%)$ \\
\hline Underweight $<18.5$ & $6(66.67 \%)$ & $1(11.11 \%)$ & $2(22.22 \%)$ & $9(100 \%)$ \\
\hline Total & 59 & 42 & 30 & 131 \\
\hline
\end{tabular}

Frequency of consumption of fast food is high among obese \& overweight students (Table 03). 
Table 03: BMI and frequency of fast food consumption

\begin{tabular}{|c|c|c|c|c|c|}
\hline \multirow[b]{2}{*}{ BMI kg/m² } & \multicolumn{5}{|c|}{ Frequency of fast food consumption } \\
\hline & $\begin{array}{c}\text { No fast } \\
\text { food }\end{array}$ & $\begin{array}{c}\text { Daily } \\
\text { consumption }\end{array}$ & $\begin{array}{l}\text { Once or more } \\
\text { in a week }\end{array}$ & $\begin{array}{l}\text { Once in a } \\
\text { month }\end{array}$ & Total \\
\hline Overweight $>24.9$ & $\begin{array}{c}2 \\
(7.14 \%)\end{array}$ & $\begin{array}{c}3 \\
(10.71 \%)\end{array}$ & $\begin{array}{c}18 \\
(64.29 \%)\end{array}$ & $\begin{array}{c}5 \\
(17.86 \%)\end{array}$ & $\begin{array}{c}28 \\
(100 \%)\end{array}$ \\
\hline Obese $>30$ & $\begin{array}{c}1 \\
(7.69 \%)\end{array}$ & $\begin{array}{c}2 \\
(15.38 \%)\end{array}$ & $\begin{array}{c}7 \\
(53.85 \%)\end{array}$ & $\begin{array}{c}3 \\
(23.07 \%)\end{array}$ & $\begin{array}{c}13 \\
(100 \%)\end{array}$ \\
\hline $\begin{array}{c}\text { Appropriate } \\
24.9\end{array}$ & $3(3.7 \%)$ & $\begin{array}{c}8 \\
(9.88 \%)\end{array}$ & $\begin{array}{c}40 \\
(45.45 \%)\end{array}$ & $\begin{array}{c}30 \\
(37.04 \%)\end{array}$ & $\begin{array}{c}81 \\
(100 \%)\end{array}$ \\
\hline Underweight $<18.5$ & $\begin{array}{c}0 \\
(0 \%)\end{array}$ & $\begin{array}{c}2 \\
(22.22 \%)\end{array}$ & $\begin{array}{c}3 \\
(33.33 \%)\end{array}$ & $\begin{array}{c}4 \\
(44.44 \%)\end{array}$ & $\begin{array}{c}9 \\
(100 \%)\end{array}$ \\
\hline Total & 6 & 15 & 68 & 42 & 131 \\
\hline
\end{tabular}

\section{Discussion}

In the present study most students (62\%) had a normal BMI. This observation was almost similar to a research showed $63.6 \%$ of students having normal BMI. ${ }^{6}$ Gopal krishnan $S$ from Tamilnadu, India reported that nearly half of the medical students were found to be in normal weight. ${ }^{7}$ Another similar study also reported a prevalence of $57 \%$ normal weight among medical students. ${ }^{8}$ In the present study overweight students were $21 \%$ and obese were $10 \%$. In our study, the sedentary life style was high among overweight and obese. A similar study from Ajman, UAE reported prevalence of overweight and obesity as $17.6 \%$ and $6.9 \% .^{9}$ In our study we found that underweight students were $7 \%$ might be due to recent trend of getting slim figure which is almost consistent with Akhter $\mathrm{H}$ et al in a Bangladeshi study, $11.3 \%$ of medical students were underweight. ${ }^{6}$ In this study more percentage of students were involved in less physical activity as well as higher frequency of fast food intake. This finding is consistent with the study conducted among the medical students of Meenakshi Medical College and Research Institute, Kanchipuram district, Tamil Nadu, India. ${ }^{8}$ Excess weight, lack of physical activity, fast food consumption and chronic stress are important determi nants of obesity and overweight. Since medical students generally spend a large part of the day at the medical college and hospital attending lectures, practicals and residing at the hostel during the study period, hence it is characterized by high levels of sedentariness and stress that may represent an important risk factor. ${ }^{10}$

\section{Limitations}

The main limitation of the present study was small sample size. Further studies are needed with larger sample to compare the dietary habits, physical activities with biochemical parameters.

\section{Conclusion}

From the study, it can be concluded that the prevalence of obesity is not higher among medical students but being overweight is coming up a significant problem. Due to the medical curriculum and the examination pattern, the students have less time to concentrate for extracurricular activities which ultimately lead them to sedentary life style and unhealthy food habits. This study reinforces the need to encourage healthy lifestyle, healthy food habits and a physically active daily routine, among medical students.

Conflict of interest: Nothing to declare. 


\section{References}

1. Majeed F. Association of BMI with diet and physical activity of female medical students at the University of Dammam, Kingdom of Saudi Arabia. J Taibah University Med Sci. 2015; 10(2):188-96.

2. Sheikh N.H., Haider A., Khan F.F., Khan F.S. and Humayun A. Body Mass Index and its Associated Factorsin Young Medical Students. Biomedica. 2014; 30 (4): 284-288.

3. Boo NY, Chia GJQ, Wong LC, chew RM, Chong W, Loo RCN. The prevalence of obesity among clinical students in a Malaysian medical school. Singapore Med J, 2010; 51(2): 126-132.

4. Manojan KK, Benny PV and Bindu A. Prevalence of Obesity and Overweight among Medical Students based on new Asia-Pacific BMI Guideline. International Journal of Preventive and Therapeutic Medicine. 2014; 2 (1): 15-17.

5. Nijhawan DM, Upadhye AJ, Upadhye JJ. Weight awareness among medical students. Int J Res Med Sci 2018; 6:84852.
6. Akhter H, Jahan N, Mahmud F, Sultana $\mathrm{N}$, Ferdous T and Akhter H.Study of Body Mass Index (BMI) on Medical Students. KYAMC Journal. 2014; 5 (1): 472-475.

7. Gopalakrishnan S, Ganeshkumar P, Prakash M V S, Christopher and Amalraj V. Prevalence of Overweight / Obesity among the MedicalStudents, Malaysia. Med J Malaysia, 2012; 67 (4): 442-444.

8. Selvaraj K, SivaprakasamP. A study on theprevalence of overweight and obesity among medical students of Kanchipuram District. National Journal of Research in Community Medicine, 2013; 2 (2): 140144.

9. Ahmed EA, Ahmed AA, Huque MS, Abdulhameed A, Khan I and Muttappallymyalil J. Obesity Among University Students: A cross-Sectional Study in Ajman, UAE. Gulf Medical Journal, 2015; 4 (2): 14-23.

10. Sarkar P, Mahadeva SK, Raghunath H and Kruthi BN.A Cross Sectional Study to Determine Overweight and Obesity among Medical Students and to correlate it with Parameters of Metabolic Syndrome. International Journal of Clinical Biochemistry and Research, 2015;2(4):210-215. 